\title{
¿CUÁNDO REALMENTE DEBEMOS INTERVENIR DE MANERA OPERATORIA LAS LESIONES DE CARIES DENTAL?
}

\section{WHEN DO WE REALLY HAVE TO CARE DENTAL CARIES INJURIES CAREFULLY?}

\author{
Prieto Ulloa José David.* \\ Práctica Privada - Docencia en Cariología y Restauradora Conservadora. Postítulo Cariología Clínica, Universidad de \\ Valparaíso. Chile. ${ }^{1}$ \\ *drjoseprieto@outlook.com
}

\begin{abstract}
Resumen
Introducción: En la actualidad, es lamentable que en general el término "caries" continúe empleándose para referirse a ambos, tanto al proceso como a la lesión, la cual se forma como resultado de dicho proceso. El proceso de caries inicia en el interior del biofilm, donde su interacción con los tejidos mineralizados de los dientes puede resultar en una lesión. Objetivo: Hacer una revisión y diferenciación crítica de las terminologías correctas de caries dental, proceso y lesión de caries, enseñando al dentista general en que situaciones clínicas realmente debe intervenir y realizar operatoria dental.
\end{abstract}

Palabras clave: Lesiones activas e inactivas, Biofilm, Proceso de caries.

\begin{abstract}
Summary:At present, it is regrettable that in general the term "caries" continues to be used to refer to both the process and the injury, which is formed as a result of that process. The caries process begins inside the biofilm, where its interaction with the mineralized tissues of the teeth can result in an injury. Objective: To make a critical review and differentiation of the correct terminologies of dental caries, process and lesion of caries, teaching the general dentist in which clinical situations really must intervene and perform dental surgery.
\end{abstract}

Key words: Active and inactive lesions, Biofilm, Cavity process.

\section{INTRODUCCIÓN}

La actividad Metabólica del Biofilm en la superficie de los dientes, es la fuerza que impulsa e inicia la pérdida de minerales en los tejidos dentarios, donde su interacción con ellos trae como consecuencia, la formación de una lesión (secuela). Lastimosamente esto es desconocido por la mayoría de clínicos, siendo esto un motivo por el cual todavía muchos dientes son intervenidos de manera operatoria innecesariamente haciendo que la pérdida de estructura dental sana sea algo irrecuperable. En todas las escuelas dentales, durante muchos años la Operatoria Dental fue sinónimo de Cariología. Sin embargo, en las últimas décadas, gracias al enorme avance del conocimiento de la enfermedad se independizó como área del saber, capaz de dar respuestas por sí sola, con sólida base biológica. ${ }^{1,2}$

Así mismo, para complementar lo expresado anterior- mente, comparto las palabras del Dr. Anders Thylstrup en su artículo "Guest Editorial: Mechanical vs Disease - oriented Treatment of Dental Caries: Educational Aspects", ${ }^{3}$ expresando lo siguiente: Universalmente, la primera experiencia del estudiante dental con el tratamiento de la caries consiste comúnmente en la preparación dientes sanos extraídos en un laboratorio preclínico, para luego ser rellenados con diversos materiales restauradores. Al hacer este ejercicio, ninguno de los estudiantes tiene la más mínima comprensión de la caries dental". 4

Los autores mencionados dejan un mensaje muy directo y claro en lo que respecta al abordaje erróneo de tratamiento de la caries dental, el cual, no es principalmente operatorio.

En la educación odontológica tradicional el problema o abordaje del manejo de la caries se ha centrado en desarrollo de habilidades manuales, más que en la comprensión de la caries como proceso. Las personas tienen "caries dental", 
nuestros dientes tienen "lesiones" y cualquier persona que los posea, se encuentra bajo riesgo de desarrollar nuevas lesiones o que las ya existentes continúen su progreso hacia la cavitación, siendo esta etapa un signo clínico del fracaso en la prevención. Por tanto, la caries dental debe considerarse como un proceso a lo largo de toda la vida del individuo, que debe ser conocido por el clínico mediante una detección clínica así como considerar los factores de riesgo de mayor poder predictivo para un control efectivo y regular de la biopelícula, a fin de evitar la cavitación, estadío donde no es posible la remineralización con terapias no invasivas y se hace necesario recurrir a terapias tradicionales restaurando el diente con diversos materiales restauradores. ${ }^{5}$

\section{DEFINICIÓN DE LA CARIES DENTAL}

Uno de los temas relevantes de esta revisión es la importancia de registrar mediante una detección clínica, la gravedad y actividad de la lesión de caries en nuestros registros clínicos, como punto de partida para evaluar el riesgo cariogénico y recomendar estrategias personalizadas en el manejo de los factores de riesgo, con el fin de controlar el proceso de caries y detener o remineralizar las lesiones.

Está claro que una de las principales barreras para realizar una correcta detección de las lesiones, su diagnóstico, evaluación de riesgo y hallazgos del ámbito de la investigación a la práctica clínica diaria, ha sido la confusión en torno a varios términos que se utilizan tanto en la odontología clínica como en la educación y la investigación al referirse a la caries dental.

Warren escribió un editorial muy provocador en el Jornal of Operative Dentistry, ${ }^{6}$ donde sugería que la precisión de las definiciones y el uso de los términos son vitales para clarificar el pensamiento y la comunicación.

De hecho, la forma en que elegimos comunicarnos puede reflejar lo que creemos o comprendemos sobre el proceso de la caries y, por tanto, como decidimos actuar.

La caries dental puede ser definida como la destrucción localizada del tejido dental duro susceptible de ser atacado por subproductos ácidos procedentes de la fermentación bacteriana de los hidratos de carbono alimenticios. Si esto continúa su curso, el proceso llevará consigo cambios perceptibles en la estructura del diente que en un principio no produce una cavidad.

Sin embargo, el proceso de caries al iniciarse en el interior del biofilm y este al encontrarse siempre en formación, siempre presente y metabólicamente activo, se considera un fenómeno natural que no puede ser prevenido y si controlado ${ }^{7}$ Entonces, si no se empieza por establecer una diferencia entre el proceso de caries y la lesión de caries, y nos centramos solo en la cavidad, se resta importancia a la necesidad de modificar los factores causales y de remineralizar las lesiones.

\section{CARIES, PROCESO Y LESIÓN}

\subsection{Caries}

Es solamente un nombre y no debe confundirse con el proceso de caries ni con la lesión (secuela clínica como resultado del proceso).

\subsection{Proceso de caries}

El proceso de caries es la secuencia dinámica de las interacciones entre la biopelícula y los dientes que se puede producir con el tiempo en una superficie dental.

Este proceso implica un cambio en el equilibrio entre los factores protectores (que ayudan a la remineralización) y los factores destructivos (que ayudan a la desmineralización), favoreciendo la desmineralización (Fig. 1) de la estructura dental con el tiempo

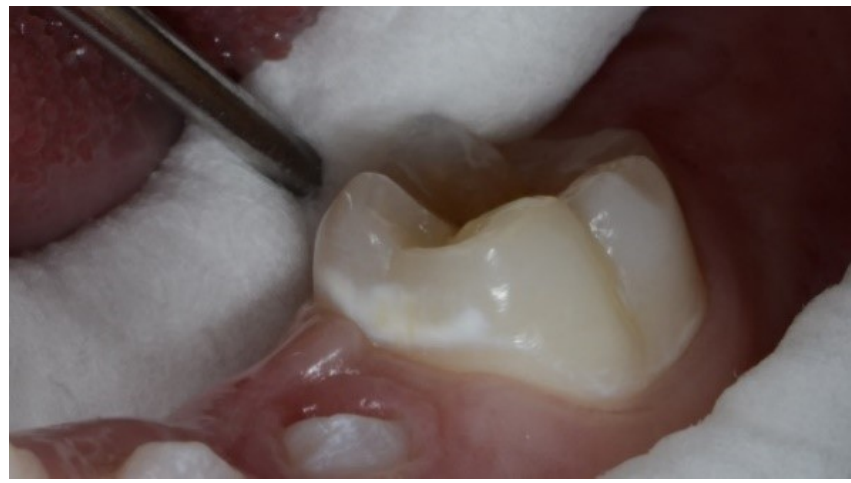

Fig. 1. Vista de un primer molar permanente inferior izquierdo donde se aprecia a nivel vestibular a lo largo del margen gingival y en proximal una lesión de mancha blanca, la cual es fácil de detectar debido a que el premolar permanente vecino aun no hace erupción en su totalidad (Cortesía - Dr. Prieto Ulloa José.)

\section{BIOFILM CARIOGÉNICO Y SU RELACIÓN CON EL PROCESO DE LA CARIES DENTAL}

Hay evidencia creciente de que la microbiota bucal natural (residente) tiene una relación simbiótica o mutualista (de cooperación) con el anfitrión, y ofrece ventajas importantes en la mantención de la salud oral. Sin embargo, en ocasiones, esta simbiosis puede ser perturbada y puede ocurrir la enfermedad (disbiosis). Por lo tanto, el cuidado oral debe centrarse en el control de los factores responsables de dicha disbiosis, manteniendo al mismo tiempo la microbiota residente normal en niveles compatibles con la salud oral, vale decir: controlar sin matar. Definimos entonces al biofilm como a una comunidad microbiana agrupada en colonias, proliferante, organizada, de mutua cooperación, ubicua y siempre enzimáticamente activa que coloniza la superficie de los dientes y los tejidos blandos que la sustentan (Fig. 23). La teoría más aceptada que explica la interacción del Biofilm en el proceso de caries dental y la predisposición 


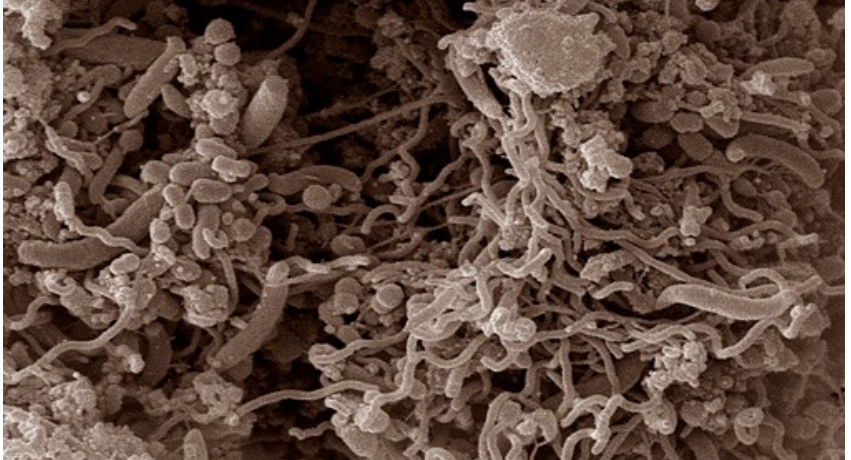

Fig. 2. Imagen de microscopía electrónica de barrido que muestra una amplia variedad de bacterias en la placa dental (Biofilm dental)

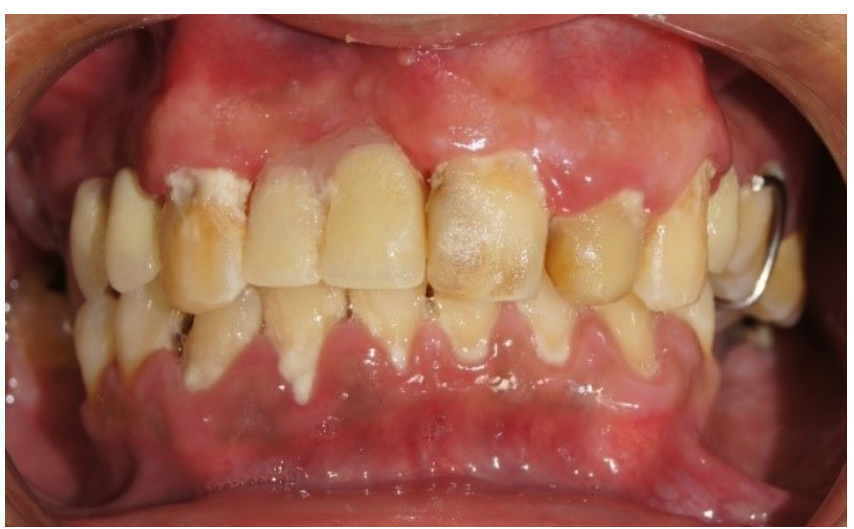

Fig. 3. Vista intraoral de placa bacteriana en un paciente de alto riesgo de caries

de un individuo a la enfermedad de caries es la denominada "Teoría de Placa Ecológica"

\subsection{Lesión de caries}

Es la consecuencia, secuela o manifestación clínica (signos y síntomas) detectable en la estructura dental (Fig. 4), como resultado del proceso de caries.

Ahora la pregunta que debemos hacernos es: ¿Cuándo realmente inician las lesiones de caries? En el año 2004 la Dra. Edwina Kidd junto al Dr. Ole Ferjeskov ${ }^{8}$ publicaron un artículo titulado "¿What Constitutes Dental Caries? Histopathology of Carious Enamel and Dentin Related to the Action of Cariogenic Biofilms", donde explican una serie de experimentos in vivo realizados por Holmen y ET AL. ${ }^{10}$ en los años 1985 y 1987 sobre dientes a los cuales se les cementaron bandas luego de ser extraídos por motivos de ortodoncia, mostraron que cuando el biofilm no es desorganizado mecánicamente mediante la técnica de cepillado, la pérdida y disolución del esmalte es inevitable, aunque en las primeras semanas no sea visible ante el ojo humano, ultraestructuralmente lo es. Esto explica como las lesiones de caries

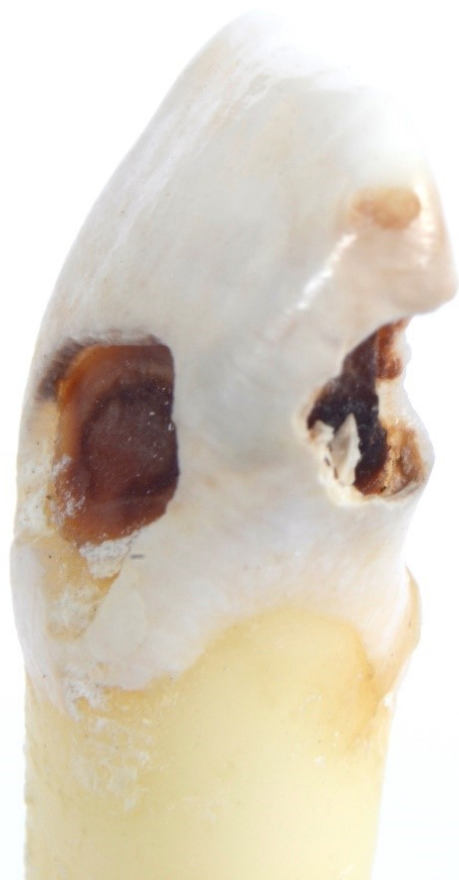

Fig. 4. Vista de un Incisivo extraído que presenta en cara vestibular y palatina - proximal una lesión de caries (Cortesía - Dr. Prieto Ulloa José.)

inician a nivel microscópico (Fig.5) y alcanzan una magnitud suficiente para ser detectadas clínicamente por el clínico, cuando el biofilm no es desorganizado o removido de manera frecuente y regular. El diagrama del Iceberg denominado así por el Dr. Nigel Pitts, ${ }^{11}$ explica como las lesiones inician a niveles sub - clínicos y se hacen visibles a niveles clínicos cuando continua la disolución del mineral del esmalte y si no se detiene dicho proceso de pérdida neta y localizada de mineral, el avance de la lesión llega hasta los estadíos más cavitados de la enfermedad.

\section{CLASIFICACIÓN DE LAS LESIONES DE CARIES}

La extensa y diversa variedad de lesiones de caries descritas en la literatura así como su actividad y progresión, determina la toma de decisión del tratamiento.

\subsection{LESIÓN DE MANCHA BLANCA}

Es una lesión no-cavitada donde la pérdida mineral neta bajo la superficie produce cambios en las propiedades ópticas del esmalte. Pueden detectarse visualmente como una pérdida de la translucidez, haciendo que la superficie del esmalte tenga un aspecto blanco (Fig. 6).

\subsection{Lesión de Mancha Marrón}

Es una lesión no-cavitada que ha alcanzado la fase en que la pérdida de mineral neta bajo la superficie junto con 


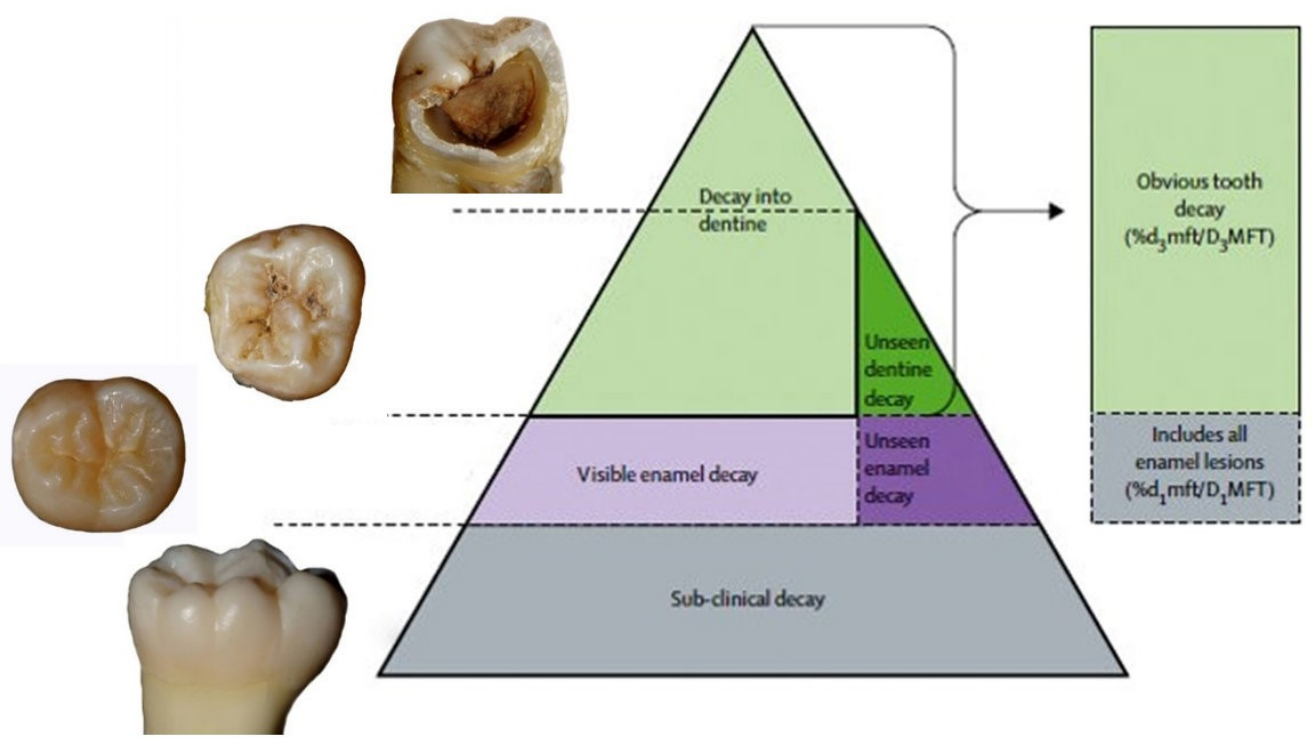

Fig. 5. Diagrama del Iceberg, Adaptado Pitts, 2004

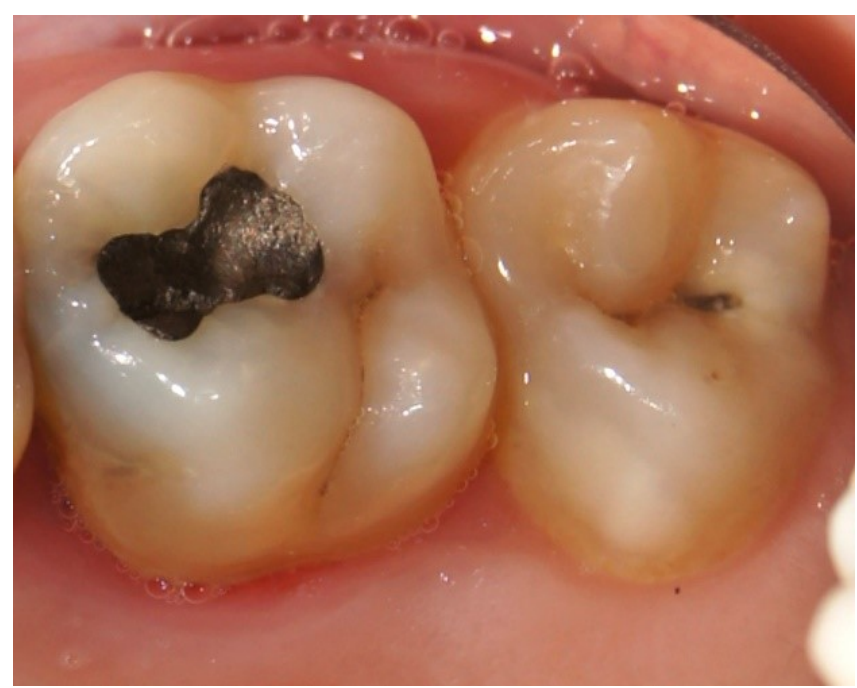

Fig. 6. Vista de una lesión de caries de mancha blanca con características de actividad en oclusal de un segundo molar superior derecho, nótese como la lesión rodea una microcavitación del esmalte que aún podría detenerse con un control efectivo del biofilm, retrasando la intervención operatoria.

la adquisición de pigmentos intrínsecos o exógenos (Fig. 7) produce cambios en las propiedades ópticas del esmalte.

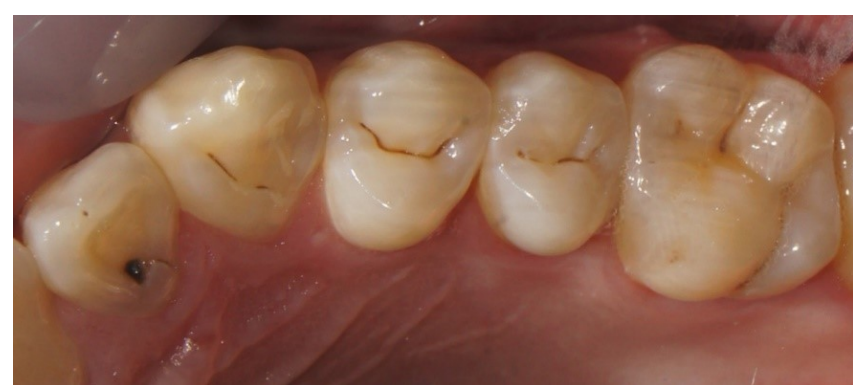

Fig. 7. Vista de lesiones de mancha marrón en premolares superiores y primer molar permanente (Cortesía - Dr. Prieto Ulloa José.)

\subsection{Lesión microcavitada}

Es una lesión de caries con una superficie que ha perdido su contorno/integridad original en esmalte o una cavidad muy pequeña donde no se detecta dentina.

\subsection{Lesión cavitada}

Es una lesión de caries con una superficie que no se encuentra macroscópicamente intacta, con una discontinuidad o abertura clara en la superficie, perceptible a la vista o el tacto. (Fig. 8)

La cavitación no necesariamente significa actividad (Fig. 8), siendo la remoción mecánica del biofilm un factor clave para la determinación clínica respecto a la actividad y gravedad de la lesión. 


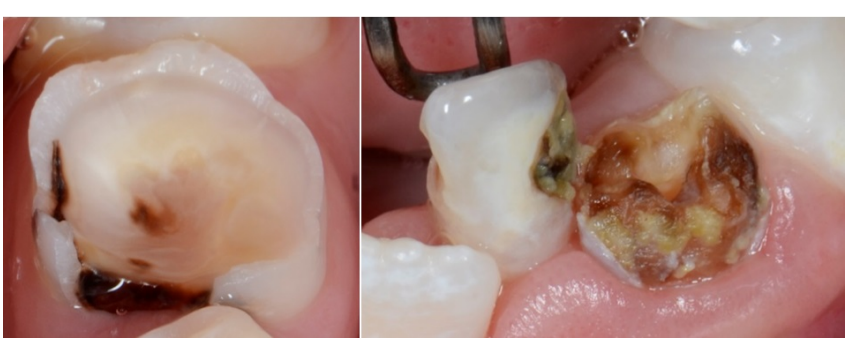

Fig. 8. Nótese que a pesar de que ambas lesiones se encuentran en un estadío más avanzado y con mayor pérdida de estructura dental, la primera se encuentra detenida y la segunda activa (Cortesía - Dr. Prieto Ulloa José. )

\section{Actividad de las lesiones cariosas}

La evaluación de la actividad de la lesión de caries no debe confundirse con la evaluación del riesgo de caries del paciente. Ambas deben realizarse durante la primera visita con el objetivo de determinar el riesgo cariogénico del paciente e implementar regímenes terapéuticos de control y modificación del biofilm.

\subsection{Lesiones de Caries activas y detenidas}

Las Lesiones de caries activas (Fig.9) tienen las siguientes características clínicas:

- Opacas "Mate” Blanquecinas.

- No reflejan luz.

- Superficie rugosa no lisa.

- Dentina blanda/cuero.

- Por otro lado, las lesiones de caries inactivas o detenidas (Fig.10) en las cuales el control del biofilm es más efectivo, presentan las siguientes características clínicas.

- Brillantes (reflejan luz).

- Superficie Lisa.

- Dentina dura.
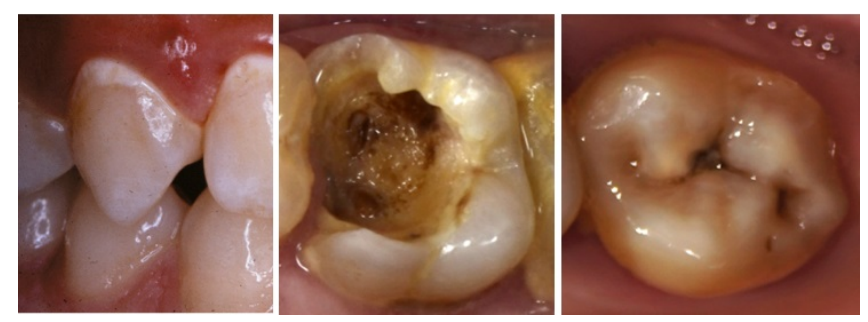

Fig. 9. De izquierda a derecha. Lesión de caries activa, se observa muy opaca, no refleja luz y al deslizar un instrumento suavemente la superficie se siente áspera, lesión de caries activa cavitada con dentina blanda al tacto, lesión de caries detenida en esmalte con microcavidad. A pesar de que el esmalte aún no se haya cavitado, existen halos opacos que indican actividad.
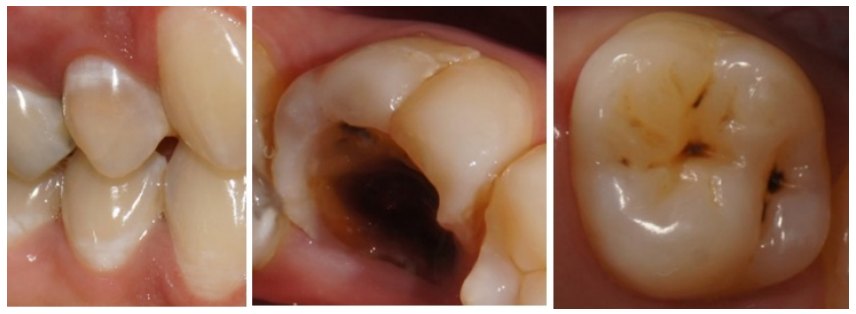

Fig. 10. De izquierda a derecha. Vista de una lesión de mancha blanca detenida, nótese como refleja la luz y al pasar un instrumento suavemente podemos sentir una superficie lisa, lesión de caries detenida de mancha marrón en cara oclusal, no necesidad de tratamiento operatorio, lesión de caries cavitada detenida.

\section{Métodos de detección Clínica de las lesiones de caries}

La detección clínica no debería confundirse con el diagnóstico, la primera evalúa las características de una lesión, su progresión y actividad, mientras que el diagnóstico en base al riesgo cariogénico busca detectar los factores de riesgo de mayor poder predictivo. Son varios los métodos de detección clínica que se han propuesto, desde los tradicionales hasta los emergentes (transiluminación, fluorescencia, conductividad eléctrica, tomografía computarizada, Rx digitales, etc.) Los nuevos métodos ofrecen ventajas en cuanto permiten una evaluación cuantitativa del proceso de caries, sin embargo, pueden llevar a malinterpretaciones, debido a que son métodos que no distinguen surcos teñidos, hipocalcificados o con restos de restauraciones o son susceptibles a variaciones de la técnica. Particularmente el (DIAGNODENT), podría ser de utilidad en el seguimiento de lesiones o superficies sospechosas en las cuales hemos instaurado tratamiento basados en métodos no invasivos. Es necesario considerar que la probabilidad de los métodos para detectar lesiones es mayor en una población con mayor prevalencia de caries, mientras que donde la prevalencia es menor, aumenta la probabilidad de "falsos positivos" y esta situación aumenta si utilizamos mayor cantidad de métodos de detección de caries para un paciente. En el siguiente artículo: (Non-cavitated carious lesions detection methods: a systematic review, ${ }^{12}$ la evidencia ha concluido que debido a las consideraciones de costo y practicidad, el método visual sigue siendo el estándar para la detección clínica en la práctica dental.

El uso del explorador (Fig.11) es un método táctil que debe considerarse un método inapropiado, ya que produce defectos en esmalte y debería sustituirse por una inspección visual meticulosa. ${ }^{13}$

\subsection{Método Radiográfico}

Las radiografías junto al método visual tienen la mejor precisión diagnóstica en lo que respecta a la detección clínica de las lesiones de caries en especial en aquellas superficies lisas libres y oclusales. Sin embargo, en las superficies proximales la detección clínica se dificulta debido a la falta de 


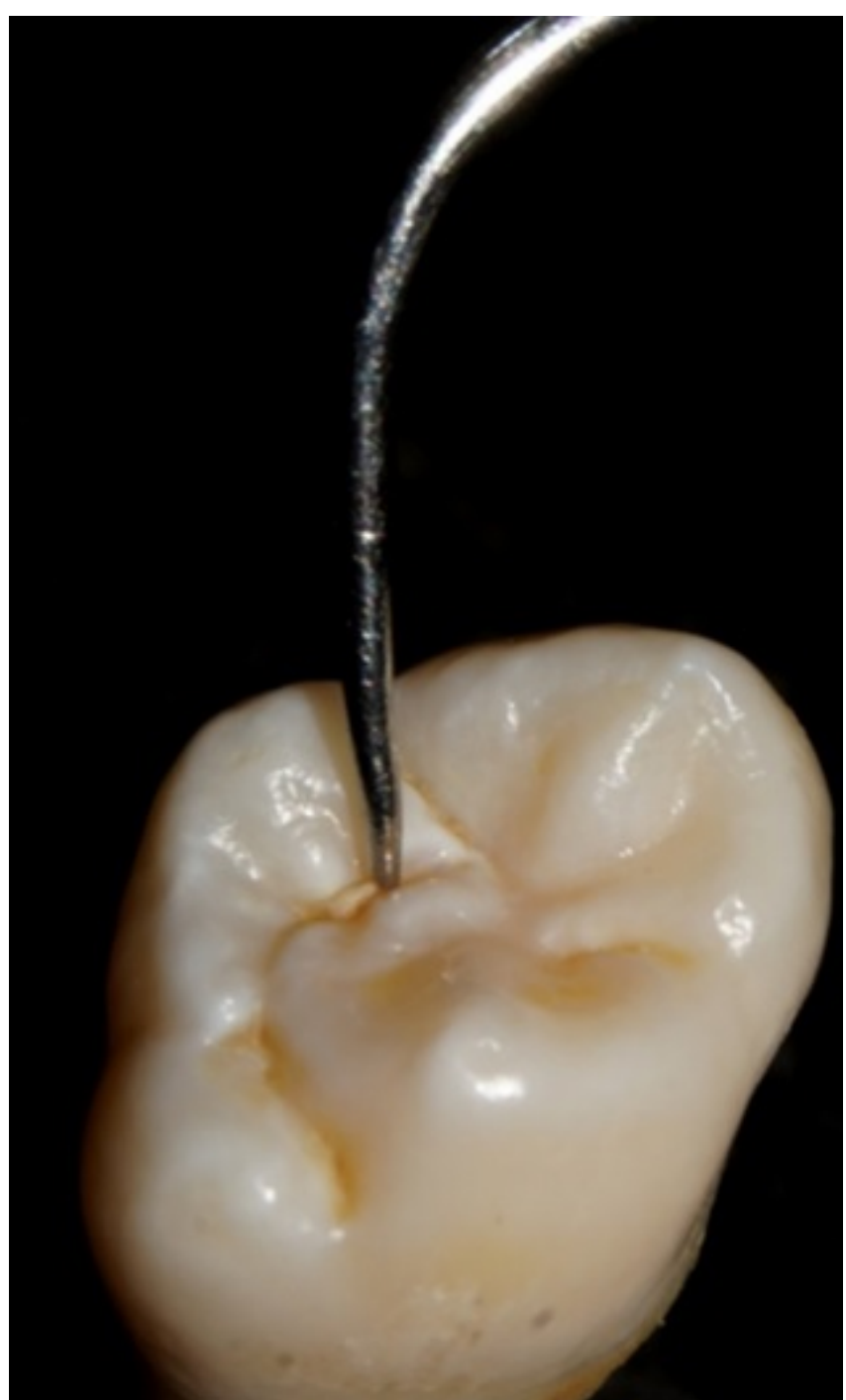

Fig. 11. Vista de un explorador colocado en la cara oclusal de un molar extraído que ilustra un método de detección clínica que no debería seguirse empleando en la práctica clínica diaria (Cortesía Dr. Prieto Ulloa José.)

acceso visual directo. Las radiografías que se recomiendan utilizar son las aletas de mordida o Bitewing (Fig. 12), pero no se recomienda basar nuestro diagnóstico definitivo en ellas, ya que las radiografías no muestran si una lesión de caries esta cavitada, no permiten diferenciar actividad, no permiten un diagnóstico más correcto y estimulan las operatorias dentales.

Las lesiones proximales, detectadas por radiografías bitewing, requerirán de una separación dental temporal electiva (Fig. 13) para determinar si están o no cavitadas. Desafortunadamente, una sola radiografía no nos permitirá determinar su actividad (progresión o detención).

Una alternativa complementaria a la detección clínica de las lesiones de caries dental, es la separación dental temporal

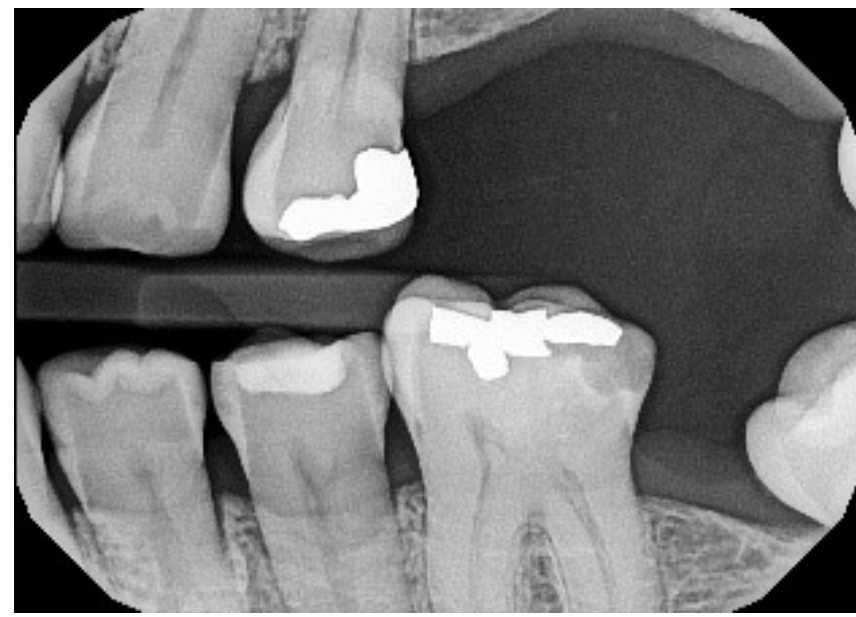

Fig. 12. Radiografía aleta de mordida evidenciando una lesión de caries proximal en distal de un primer premolar inferior derecho.

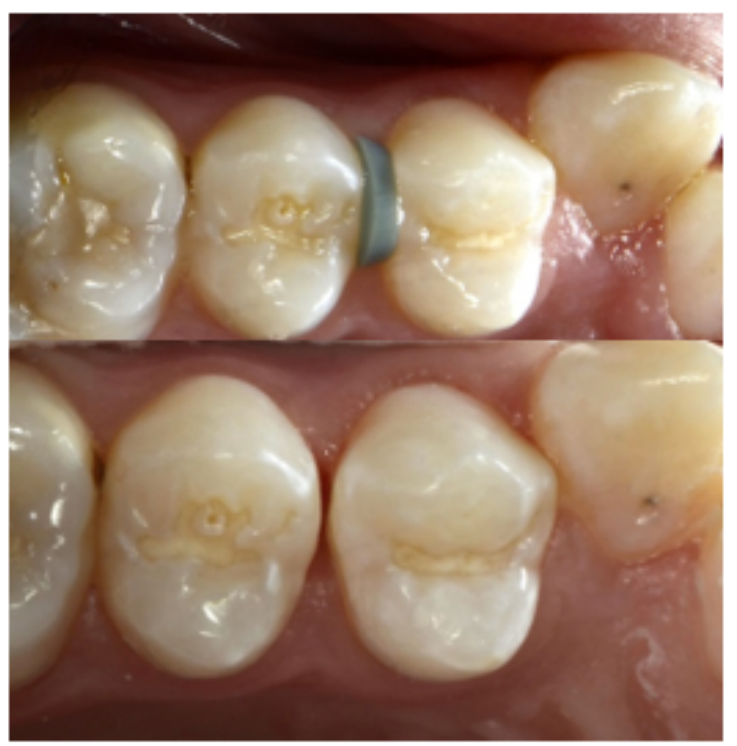

Fig. 13. Separación Dental Temporal Electiva en dos premolares superiores, nótese que 48 horas después se logró una separación suficiente para detectar visualmente si las lesiones detectadas previamente en radiografía bitewing estaban activas o detenidas, cavitada o no cavitada.(Caso cedido por la Facultad de Odontología de la Universidad de Valparaíso

electiva, que consiste en la colocación de una goma o elástico por unas 48 horas usado generalmente en ortodoncia. El único estudio realizado a la fecha fue el de Deery et al (2000) en 182 niños de Letonia comparó la separación dental temporal electiva vs FOTI (Digital Fiber optic transillumination), encontrando que la SDTE era superior al FOTI para la detección de lesiones proximales. En el mismo estudio Deery et al ${ }^{14}$ concluye que el FOTI puede ser un método complementario, 
particularmente cuando no se cuenta con radiografía por su bajo costo en comparación con la radiografía o métodos basados en laser. ${ }^{15}$

Sin embargo, junto a la separación temporal, el análisis de los otros dientes presentes en boca, así como la salud gingival en el área proximal y la presencia de biofilm, o la detección de múltiples lesiones incipientes, junto a la historia de riesgo cariogénico y análisis de dieta, podrán orientar al clínico en la evaluación de la actividad de la lesión.

Entonces, ¿Qué debemos detectar? Las lesiones de caries iniciales o aquellas que ya han alcanzado una magnitud suficiente para ser visibles por el clínico pero aún no se encuentran en un estadío de cavitación son aquellas que debemos detectar de manera precoz, a fin de evitar la cavidad, situación donde no es posible remineralizar con terapias no invasivas haciéndose necesario recurrir al método quirúrgico y tradicional de restauración plástica de la lesión.

\section{CONCLUSIÓN}

Tanto la lesión como su progreso pueden ser controlados en cualquiera de sus etapas, incluso en estado de cavitación siempre y cuando podamos limpiar y desorganizar el biofilm en forma frecuente con cepillado y pastas que contengan fluoruros. Esto significa que el principal tratamiento de la caries es "no operatorio" e involucra un eficiente control del biofilm y una dieta adecuada.

¿Cuándo debemos intervenir de manera operatoria? Cuando exista una lesión de caries que el paciente no pueda limpiar debido a sus características y difícil acceso a la remoción mecánica del biofilm.

En su artículo (The implications of the new paradigm of dental caries. J Dent. 2011 Dec; 39 Suppl 2:S3-8. Epub 2011 Nov 10), la Dra. Kidd establece claramente que, la operatoria dental es parte del control del biofilm, ya que transforma una cavidad imposible de cepillar en una superficie lisa, donde es más fácil desorganizar al biofilm. Por lo tanto, en aquellos pacientes con lesiones activas y detenidas en base al riesgo de caries, las siguientes medidas deberían aplicarse, asociadas a factores sociales y/o del comportamiento, que puedan ser relevantes:

1) Higiene oral eficiente

2) Dieta adecuada en calidad y oportunidad

3) Apropiada exposición a los fluoruros

4) Estimulación del flujo salival.

Según la Federación Dental Internacional (FDI), las lesiones cavitadas deben ser intervenidas en forma mínima y únicamente cuando una lesión no se pueda mantener en un estado libre de placa.

En cuanto al costo-efectividad de los tratamientos dentales, los estudios epidemiológicos nos muestran que el actual 1 modelo de enseñanza de la odontología es carísimo y poco eficiente, toda vez que el hacer más restauraciones no da como resultado a largo plazo dientes más funcionales o menos lesiones de caries. Por eso la Dra. Kidd piensa que educar más odontólogos tradicionales puede ser un error muy caro en lo que al control del proceso concierne.

Finalmente, puntualiza que resulta "irónico" que los odontólogos ganen más dinero con la operatoria dental y tratamientos especializados, en consideración que la prevención y el control del proceso pueden ser realmente mucho más económico.

La caries dental es un proceso continuo a lo largo de toda la vida de una persona, por tanto todas las personas que tienen dientes en boca se encuentran en riesgo y deben cepillarse al menos 2 veces al día con pastas que contengan fluoruros y hacerlo desde la "cuna hasta la tumba" para un regular y efectivo control del biofilm

Conflicto de intereses y financiamiento El autor declara no tener conflicto de intereses, haber cumplido con los requisitos de autoría y haber autofinanciado este artículo.

\section{Referencias}

1 Kidd EAM, Ole Fejerskov. ¿What Constitutes Dental Caries? Histopathology of Carious Enamel and Dentin Related to the Action of Cariogenic Biofilms. J Dent Res 83(Spec Iss C):C35-C38, 2004

2 Philip D. Marsh. Microbiology of Dental Plaque Biofilms and Their Role in Oral Health and Caries. Dent Clin N Am 54 (2010) 441-454

3 Phil D. Marsh, David A. Head, Deirdre A. Devine. Ecological Approaches to Oral Biofilms Control without Killing. Caries Res 2015;49(suppl 1):46-54

4 Gustavo Moncada C. Iván Urzúa A. Cariología Clínica: Bases Preventivas y Restauradoras, 2008.

5 Hendrik Meyer - Lueckel, Sebastian Paris, Kim R. Ekstrand. Manejo de la caries: Ciencia y Práctica Clínica, 2015.

6 Margherita Fontana, Douglas A. Young, Nigel B. Pitts. Defining Dental Caries for 2010 and Beyond. Dent Clin N Am 2010; 54: 469-78

7 B. Nyvad, V. Baelum. Reliability of a New Caries Diagnostic System differentiating between active and inactive caries lesions. Caries Research 1999;33:252-260.

8 Edwina Kidd: The implications of the new paradigm of dental caries. J Dent. 2011 Dec; 39 Suppl 2:S3-8. Epub 2011 Nov 10.

9 Gomez J, M. Tellez, I.A. Pretty. Non - Cavitated Carious Lesions Detection Methods: a systematic review. Community Dent Oral Epidemiology 2013;41; 55-66

10 A. I. Ismail. Visual and Visuo-tactile Detection of Dental Caries. Journal of dental Research 83.

11 Kidd EAM. How "Clean" must a cavity be before restoration?. Caries Research 2004;38:305-313.

12 Anders Thylstrup Guest Editorial: Mechanical vs Disease oriented Treatment of Dental Caries: Educational Aspects, 1989. 
13 Iain A. Pretty: Caries detection and diagnosis: Novel technologies Journal of Dentistry 34 (2006) 727- 739

14 Glenn K. Rochlen, DDS, Mark S. Wolff, DDS, PhD: Technological Advances in Caries Diagnosis, Dent Clin N Am 55 (2011) 441-452

15 Santiago S. Gómez, DDS/ Juan E. Onetto, DDS/ Sergio A. Uribe, DDS/ Claes - Goran Emilson, DDS, PHD: Therapeutic Seal of Approximal incipient noncavitated carious lesions: Technique and case reports, (Quintessence Int 2007;38:91.e99-105)

Recibido: 8 de enero de 2017.

Aceptado: 20 de marzo de 2017. 